\title{
MicroRNA-19b inhibitors can attenuate the STAT3 signaling pathway in NPC C666-1 cells
}

\author{
LI-HUI BIAN $^{1,2^{*}}$, JING-LING DUAN $^{2,3^{*}}$, CHEN ZHOU $^{1,2^{*}}$, GUO-WEN SHEN $^{1,2}$, \\ XIAO-YU WANG ${ }^{1,2}$, YANG YANG ${ }^{1,2}$, XIAO-LING ZHANG $^{4}$ and SHENG-JUN XIAO ${ }^{1}$
}

\author{
${ }^{1}$ Department of Pathology, The Second Affiliated Hospital, Guilin Medical University, Guilin, Guangxi 541199; \\ ${ }^{2}$ Department of Pathology and Pathophysiology, Graduate School of Guilin Medical University, Guilin, Guangxi 541004; \\ ${ }^{3}$ Department of Pathology, Fudan University Shanghai Cancer Center, Shanghai 200032; ${ }^{4}$ Department of Physiology, \\ Faculty of Basic Medical Sciences, Guilin Medical University, Guilin, Guangxi 541004, P.R. China
}

Received July 4, 2019; Accepted January 14, 2020

DOI: $10.3892 / \mathrm{mmr} .2020 .11112$

\begin{abstract}
MicroRNA (miR)-19b is expressed in various types of tumors and may serve as a potential therapeutic target. The miR-17-92 cluster is upregulated in nasopharyngeal carcinoma (NPC) tissues and cells. miR-19b is a member of the miR-17-92 cluster; however, its expression and function in NPC are largely unknown. The present study aimed to investigate the expression and function of miR-19b in NPC cells. The miRCURY LNA ${ }^{\mathrm{TM}}$ miRNA Inhibitor (miR-19b inhibitor and negative control) were transfected into C666-1 cells. The proliferation, apoptosis and migration of the cells were subsequently detected by the Cell Counting Kit-8 assay, flow cytometry and Transwell assay, respectively. Additionally, the expression of STAT3 signaling pathway-associated proteins [STAT3, pSTAT3 and suppressor of cytokine signaling 1 (SOCS1)] and the transcriptional targets of pSTAT3 [Bcl-2, myeloid leukemia protein 1 (Mcl-1) and cyclin D1] were detected by western blotting. The miR-19b inhibitor inhibited proliferation and migration and induced apoptosis of C666-1 cells. Furthermore, the miR-19b inhibitor upregulated the expression of SOCS1, a predicted target gene of miR-19b, and decreased the phosphorylation of STAT3 at Tyr705 and Ser727. These data indicated that upregulation of SOCS1, an endogenous inhibitor of STAT3 phosphorylation, attenuated
\end{abstract}

Correspondence to: Professor Sheng-Jun Xiao, Department of Pathology, The Second Affiliated Hospital, Guilin Medical University, 212 Renmin Road, Lingui, Guilin, Guangxi 541199, P.R. China

E-mail: xiaoshengjun@glmc.edu.cn

Dr Xiao-Ling Zhang, Department of Physiology, Faculty of Basic Medical Sciences, Guilin Medical University, 109 Huancheng Bei 2nd Road, Guilin, Guangxi 541004, P.R. China

E-mail: rose2006@glmc.edu.cn

*Contributed equally

Key words: nasopharyngeal neoplasms, microRNAs, STAT3 transcription factor, cell proliferation, apoptosis the STAT3 signaling pathway in C666-1 cells. Moreover, the expression level of the proproliferative protein cyclin D1 and antiapoptotic proteins $\mathrm{Mcl}-1$ and $\mathrm{Bcl}-2$ was significantly decreased following transfection with the miR-19b inhibitor. The aforementioned three proteins are downstream transcriptional targets of the activated STAT3 signaling pathway. The results of the present study revealed that inhibition of miR-19b negatively modulated the malignant behavior of NPC cells via the STAT3 signaling pathway. Therefore, miR-19b inhibition may serve as a novel therapeutic target for the treatment of NPC.

\section{Introduction}

Nasopharyngeal carcinoma (NPC) is a type of head and neck cancer endemic in Southeast Asia, and is closely related to Epstein-Barr virus (EBV) infection (1). Despite the improvement in local tumor control achieved by more precise imaging modalities and radiotherapy, the 5-year survival rate of patients with NPC remain unsatisfactory, primarily due to distant metastasis (2). Therefore, there is a requirement for the elucidation of the molecular mechanisms underlying the pathogenesis of NPC as well as the development of novel therapeutic strategies.

MicroRNAs (miRNA/miR) are a class of small, non-protein-coding RNAs that function in RNA silencing and post-transcriptional regulation of gene expression (3). miRNAs are also known to play key roles in cancer, where they serve as oncomirs or tumor suppressors (4). miRNAs have been found to regulate genes involved in multiple cellular processes, including development, differentiation, proliferation and apoptosis (5). The modulation of miRNAs, based on two major approaches (miRNA mimics and miRNA antagonists/inhibitors), is currently being investigated for the clinical development of therapeutic miRNAs $(6,7)$.

miR-19b, also termed miR-19b-1 or miR-19b-1-5p, is upregulated in several types of cancer and has been reported to serve as an oncomir (8). miR-19b serves as a prognostic biomarker for breast cancer and promotes tumor progression through the PI3K/AKT signaling pathway (9). A previous study reported that miR-19b decreases apoptosis, promotes proliferation and induces tumorigenicity in multiple myeloma 
cells by targeting phosphatase and tensin homolog (10). The miR-17-92 cluster, which includes miR-17-5p, miR-17-3p, miR-18a, miR-19a, miR-20a, miR-19b-1 and miR-92-1, was reported to be upregulated in NPC (11). However, the role of miR-19b in NPC has not been fully elucidated. Therefore, the present study investigated the function of miR-19b, as well as the therapeutic effect of miR-19b inhibitors, in NPC cells.

\section{Materials and methods}

Cell lines and culture. EBV-positive cells C666-1 and HK1-EBV were kindly provided by Professor Sai Wah Tsao (The University of Hong Kong, Hong Kong, China) (12). 5-8F, SUNE1 and SXSW-1489 were kindly provided by Professor Xiao Dong (Southern Medical University, Guangzhou, China) (13) and Professor Weiyi Fang (Southern Medical University) (14). NPC cell lines (C666-1, HK1-EBV, 5-8F, SUNE1) and the immortalized nasopharyngeal epithelial cell line (SXSW-1489) were cultured in Roswell Park Memorial Institute (RPMI)-1640 medium (Gibco; Thermo Fisher Scientific, Inc.) supplemented with $10 \%$ heat-inactivated fetal bovine serum (FBS; Gibco; Thermo Fisher Scientific, Inc.). C666-1 cells were cultured with the addition of $10 \mu \mathrm{g} / \mathrm{ml}$ streptomycin (Gibco; Thermo Fisher Scientific, Inc.). The cells lines were maintained in a humidified atmosphere at $37^{\circ} \mathrm{C}$ and $5 \% \mathrm{CO}_{2}$.

Reverse transcription-quantitative PCR analysis for $m i R-19 b$ expression. Total RNA from cultured (C666-1, HK1-EBV, 5-8F, SUNE1, SXSW-1489) cells and lenses was extracted using TRIzol $^{\circledR}$ reagent (cat. no. 15596026, Thermo Fisher Scientific, Inc.) according to the manufacturer's protocol. Genomic DNA was subsequently removed using DNase I. cDNA was synthesized using the Mir-X miRNA First-Strand Synthesis kit (Clontech Laboratories, Inc.) and the following primers: U6, AACGCTTCA CGAATTTGCGT; and miR-19b, GTCGTATCCAGTGCAGGG TCCGAGGTATTCGCACTGGATACGACTCAGT. The expression levels of miR-19b and the internal control U6 were quantified by qPCR using a SYBR Premix Ex Taq II kit (Takara Bio, Inc.) and an ABI Prism 7,000 sequence detection system (Applied Biosystems; Thermo Fisher Scientific, Inc.). The following primer pairs were used: U6 forward, CTCGCTTCGGCAGCA CA and reverse, AACGCTTCACGAATTTGCGT; and mir-19b forward, TGTGCAAATCCATGCAAA and reverse, GTGCAG GGTCCGAGGTATTC. miRNA levels were quantified using the $2^{-\Delta \Delta \mathrm{Cq}}$ method and normalized to the internal control U6.

Transient transfection of miRNA-19b inhibitors. The miRCURY LNA ${ }^{\mathrm{TM}}$ miRNA Inhibitor [consisting of an miR-19b inhibitor and a negative control (NC)] was obtained from Qiagen, Inc. The sequences of the miRNA are proprietary information. The miRNAs were transiently transfected into C666-1 cells at a working concentration of $15 \mu \mathrm{M}$ using X-tremeGENE siRNA Transfection Reagent (Roche Diagnostics) following the manufacturer's protocol.

Cell Counting Kit-8 (CCK-8) proliferation assay. A total of $2 \times 10^{3}$ C666-1 cells per well were seeded in a 96-well plate in a final volume of $100 \mu \mathrm{l}$ and transfected with miRNAs. The effect of the miR-19b inhibitor on cell proliferation was subsequently determined using the CCK-8 assay at
$6,12,24$ and $48 \mathrm{~h}$ post-transfection. A total of $10 \mu \mathrm{lCCK}-8$ solution (Dojindo Molecular Technologies, Inc.) was added to each well and incubated for $4 \mathrm{~h}$ at $37^{\circ} \mathrm{C}$. The optical densities of the resultant purple solutions were measured at a wavelength of $450 \mathrm{~nm}(15)$.

Transwell migration assay. Transwell chambers (24-well insert; Corning, Inc.) were used to analyze cell migration. At $48 \mathrm{~h}$ post-transfection, a total of $2 \times 10^{4}$ C666-1 cells in serum-free RPMI-1640 medium were seeded into the upper chamber of the insert. RPMI-1640 medium containing $10 \%$ FBS was added to the lower chamber to serve as a chemo-attractant. Cells were allowed to migrate for $24 \mathrm{~h}$. The cells on the upper membrane surface were removed using a cotton bud and the cells on the lower membrane surface were fixed with $4 \%$ formaldehyde. The cells were subsequently stained with $0.1 \%$ crystal violet (Amresco, LLC) and the migrated cells were counted in three random-selected fields. The result of migrated cells was observed and photographed under light microscope (Olympus, Japan).

Flow cytometry assay. C666-1 cells were harvested $48 \mathrm{~h}$ post-transfection by trypsin digestion without EDTA and stained using the APC-Annexin V/7-AAD Dual Staining Cell Apoptosis Detection kit (BD Biosciences) according to the manufacturer's instructions. The cells were subsequently analyzed with a flow cytometer. The cells in Q2 (late-stage apoptosis) and Q4 (early-stage apoptosis) were considered to be apoptotic cells.

Western blot analysis. At 48 h post-transfection, cell lysates were harvested. The lysis buffer used RIPA buffer and PMSF (cat. no. R0020, 1:100, Beijing Solarbio Science \& Technology, Inc.). Proteins were separated by $10 \%$ SDS-PAGE separating gel and 5\% SDS-PAGE stacking gel, and then electrophoretically transferred onto a polyvinylidene difluoride membrane. The membrane was subsequently incubated with primary antibodies against $\beta$-actin (cat. no. TA-09; 1:5,000; OriGene Technologies, Inc.), STAT3 (cat. no. sc-8019; 1:2,000; Santa Cruz Biotechnology, Inc.), suppressor of cytokine signaling (SOCS) 1 (cat. no. PA5-27239; 1:2,000; Thermo Fisher Scientific, Inc.), p-STAT3 (Tyr705; cat. no. G.374.10; 1:2,000; Thermo Fisher Scientific, Inc.), p-STAT3 (Ser727; cat. no. PS727.2; 1:2,000; Thermo Fisher Scientific, Inc.), cyclin D1 (cat. no. OTI1F7; 1:1,000; OriGene Technologies, Inc.), Bcl-2 (cat. no. OTI2E5; 1:1,000; ZSGB-BIO), myeloid leukemia protein 1 (Mcl-1; cat. no. OTI3A12; 1:1,000; OriGene Technologies, Inc.) overnight at $4^{\circ} \mathrm{C}$ in Primary Antibodies Dilution Buffer (cat. no. P0023A; Beyotime Institute of Biotechnology). Following primary antibody incubation, the membrane was incubated with peroxidase-conjugated goat anti-mouse IgG (H+L; cat. no. ZB-2305; 1:5,000; ZSGB-BIO) and peroxidase-conjugated goat anti-rabbit $\mathrm{IgG}(\mathrm{H}+\mathrm{L}$; cat. no. ZB-2301; 1:5,000; OriGene Technologies, Inc.) secondary antibodies for $1 \mathrm{~h}$ at room temperature. The protein bands were visualized using the ECL Western Blot Kit detection system (Thermo Fisher Scientific, Inc.). Protein expression was quantified with $\beta$-actin as the loading control at least three times and analyzed by Image-J (version1.50i, National Institutes of Health). 
Statistical analysis. Data are presented as the mean \pm SEM of three independent experiments. One-way ANOVA test was used to analyze the groups. Multiple comparisons were made using the Tukey's post hoc test. Statistical analysis was performed using SPSS software (version 20; IBM Corp). $\mathrm{P}<0.05$ were considered to indicate a statistically significant difference.

\section{Results}

miR-19b is upregulated in the majority of NPC cell lines. RT-qPCR revealed that miR-19b was upregulated NPC cells (C666-1, 5-8F and SUNE1) compared with the nasopharyngeal epithelial cell line SXSW-1489. However, no statistical difference in miR-19b expression was observed between HK1-EBV and SXSW-1489 cells (Fig. 1). As C666-1 is the only NPC cell line consistently harboring EBV during in vitro propagation (16), this cell line was selected for subsequent miR-19b interference.

miR-19b inhibitor inhibits the proliferation of C666-1 cells. The miR-19b inhibitor or NC were transiently transfected into C666-1 cells and the effect on proliferation was subsequently investigated. As shown in Fig. 2, the miR-19b inhibitor inhibited the proliferation of C666-1 cells compared with the NC.

miR-19b inhibitor promotes the apoptosis of C666-1 cells. The miR-19b inhibitor or NC were transiently transfected into C666-1 cells and the effect on apoptosis was subsequently investigated. As shown in Fig. 3, flow cytometry revealed that the miR-19b inhibitor promoted the apoptosis of C666-1 cells compared with the NC.

miR-19b inhibitor inhibits the migration of C666-1 cells. The effect on the migration of C666-1 cells was investigated $48 \mathrm{~h}$ post-transfection using a Transwell assay. As shown in Fig. 4, the migration of C666-1 cells was significantly inhibited following transfection with the miR-19b inhibitor, compared with the NC group.

miR-19b inhibitor attenuates STAT3 signaling in C666-1 cells. Western blotting revealed that the expression levels of pSTAT3-Tyr705 and pSTAT3-Ser727 in C666-1 cells decreased following transfection with the miR-19b inhibitor compared with the NC. Furthermore, the expression level of SOCS1, an endogenous inhibitor of STAT3 phosphorylation (17), increased following transfection with the miR-19b inhibitor compared with the NC (Fig. 5). Collectively, these results suggested that the miR-19b inhibitor specifically targeted the STAT3 signaling pathway.

miR-19b inhibitor downregulates the expression of the STAT3 signaling pathway downstream effectors. To explore the effect of the miR-19b inhibitor on the expression of the downstream effector genes of the STAT3 signaling pathway, the expression levels of the proliferation-associated gene cyclin D1 and the apoptosis-associated genes Mcl-1 and Bcl-2 were detected by western blotting. These three proteins were downregulated following transfection with the miR-19b inhibitor compared with the NC (Fig. 6), further suggesting that the STAT3 signaling pathway was impaired. Furthermore, the change in malignant

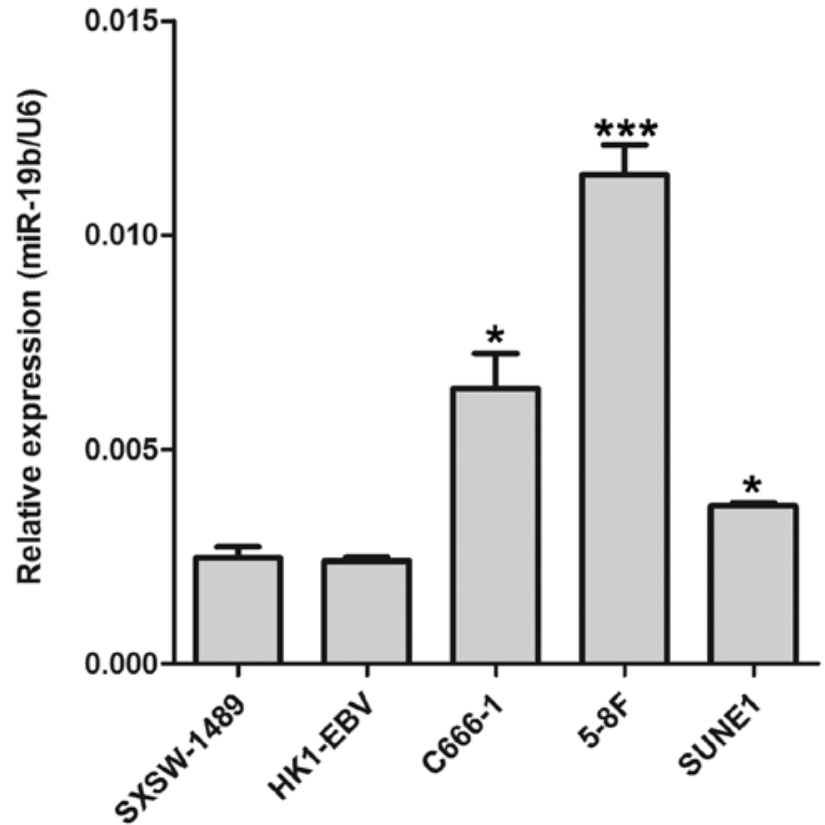

Figure 1. miR-19b expression in NPC and immortalized nasopharyngeal epithelial cells was detected by reverse transcription-quantitative PCR. miR-19b was upregulated in three NPC cell lines (C666-1, 5-8F, and SUNE1) compared with the immortalized nasopharyngeal epithelial cell line SXSW-1489. ${ }^{*} \mathrm{P}<0.05 ;{ }^{* * *} \mathrm{P}<0.001$ vs. SXSW-1489. miR, microRNA; NPC, nasopharyngeal carcinoma.

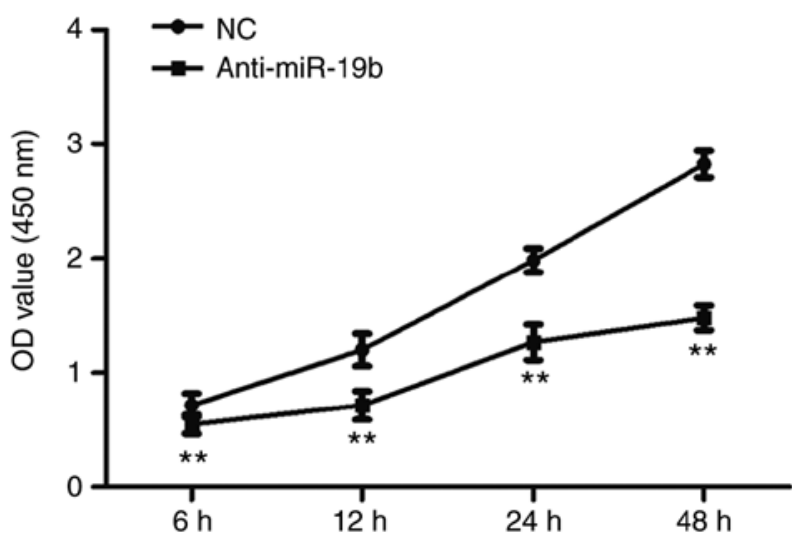

Figure 2. miR-19b inhibitor inhibited the proliferation of C666-1 cells C666-1 cells were transfected with the miR-19b inhibitor for 6, 12, 24 and 48 h. The Cell Counting Kit- 8 assay revealed that C666-1 cells transfected with the miR-19b inhibitor exhibited decreased proliferation compared with cells transfected with the NC. ${ }^{* *} \mathrm{P}<0.01$ vs. NC. miR, microRNA; $\mathrm{NC}$, negative control.

biological behaviors such as proliferation, apoptosis and migration may have been mediated by the downstream effectors of the STAT3 signaling pathway.

\section{Discussion}

miR-19b, as a member of the miR-17-92 cluster, has been revealed to serve as an oncomir in several types of tumors $(18,19)$. miR-19b promotes cell proliferation, migration and angiogenesis and inhibits cell apoptosis in several malignancies $(20,21)$. The miR-17-92 cluster has been reported to be upregulated in NPC tissues and cell lines (22). Furthermore, the miR-17-92 
A

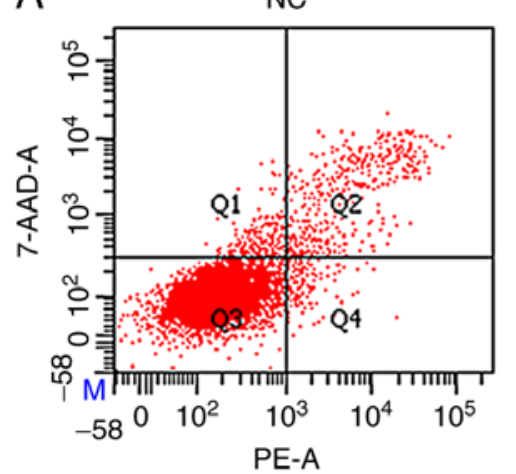

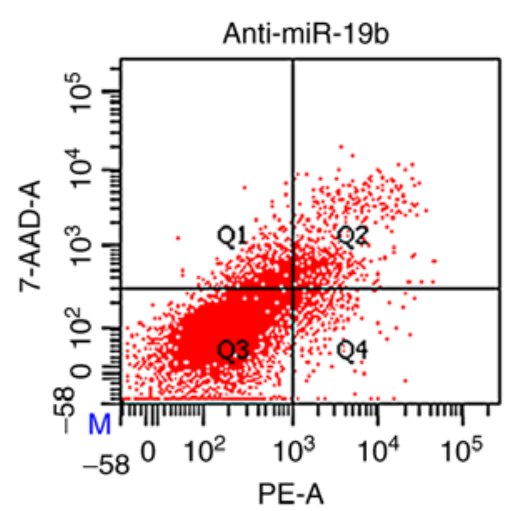

B

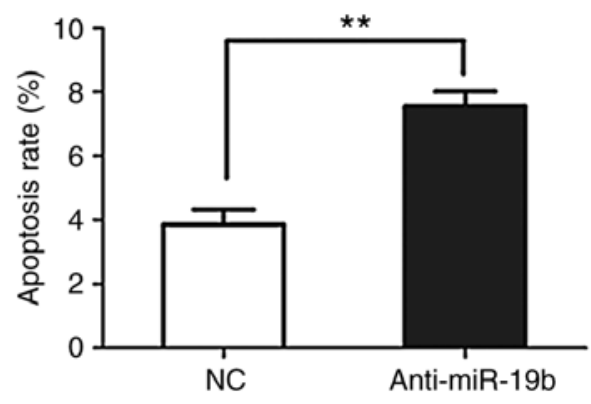

Figure 3. miR-19b inhibitor increased the apoptosis of C666-1 cells. (A) At $48 \mathrm{~h}$ post-transfection, C666-1 cells transfected with the miR-19b inhibitor exhibited increased apoptosis compared with the NC, as demonstrated by flow cytometry. (B) Bar graphs show percentages of apoptotic cells. ${ }^{* *} \mathrm{P}<0.01 \mathrm{vs}$. NC. miR, microRNA; NC, negative control.

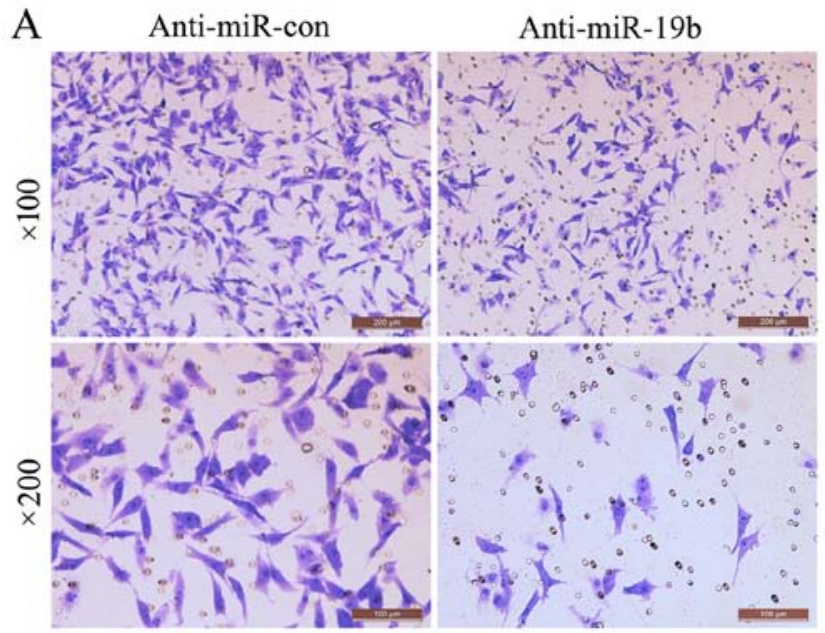

B

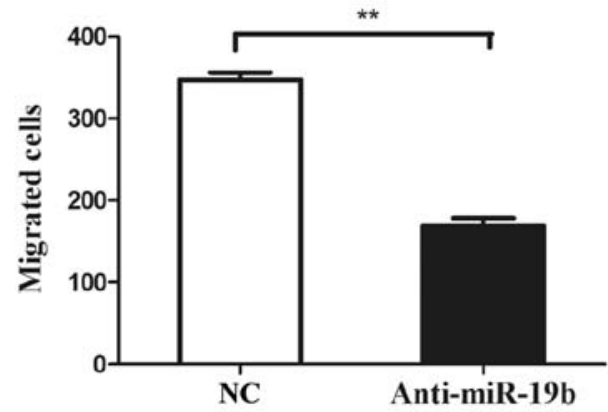

Figure 4. miR-19b inhibitor inhibited the migration of C666-1 cells. (A) At $48 \mathrm{~h}$ post-transfection, C666-1 cells transfected with the miR-19b inhibitor exhibited decreased migration compared with the NC, as demonstrated by the Transwell assay. (B) Number of migrated cells. ${ }^{* *}$ P $<0.01$ vs. NC. miR, microRNA; NC, negative control.

A

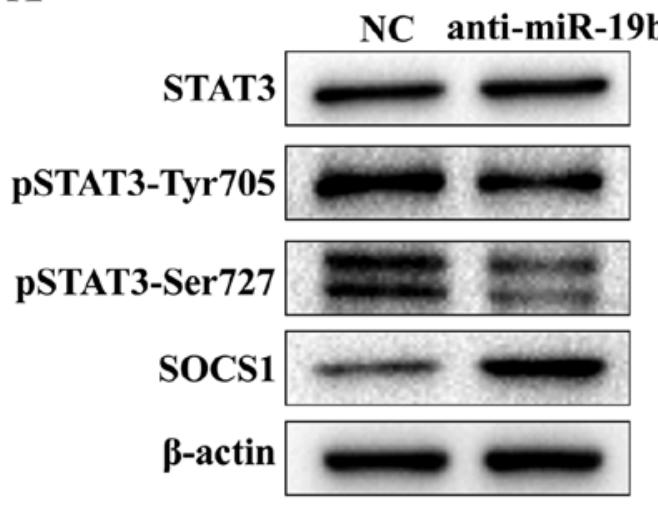

B

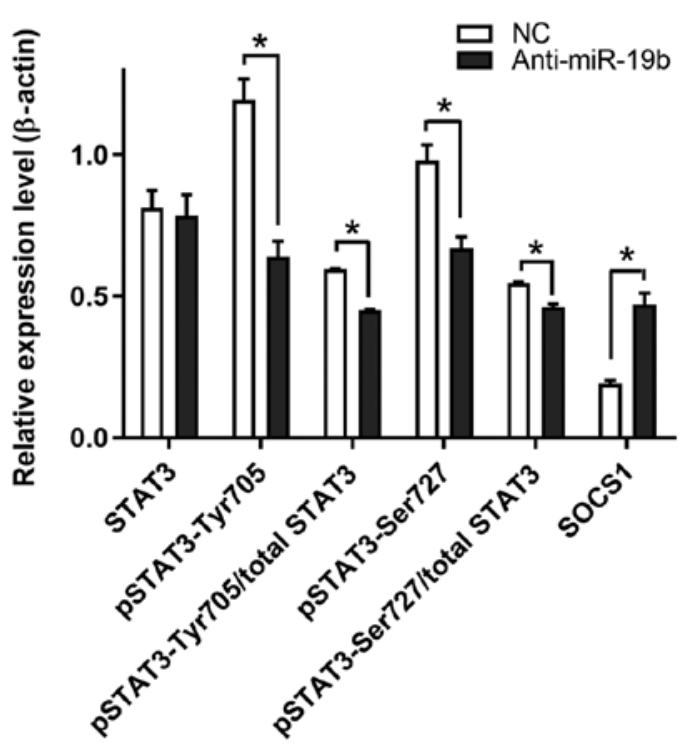

Figure 5. miR-19b inhibitors upregulated the expression of SOCS1 and decreased the expression of pSTAT3. (A) C666-1 cells were transfected with the miR-19b inhibitor or $\mathrm{NC}$ and the protein levels were determined by western blotting $48 \mathrm{~h}$ post-transfection. (B) Protein expression was semi-quantified. ${ }^{*} \mathrm{P}<0.05$. miR, microRNA; NC, negative control. SOCS, suppressor of cytokine signaling 1; p, phosphorylated. 

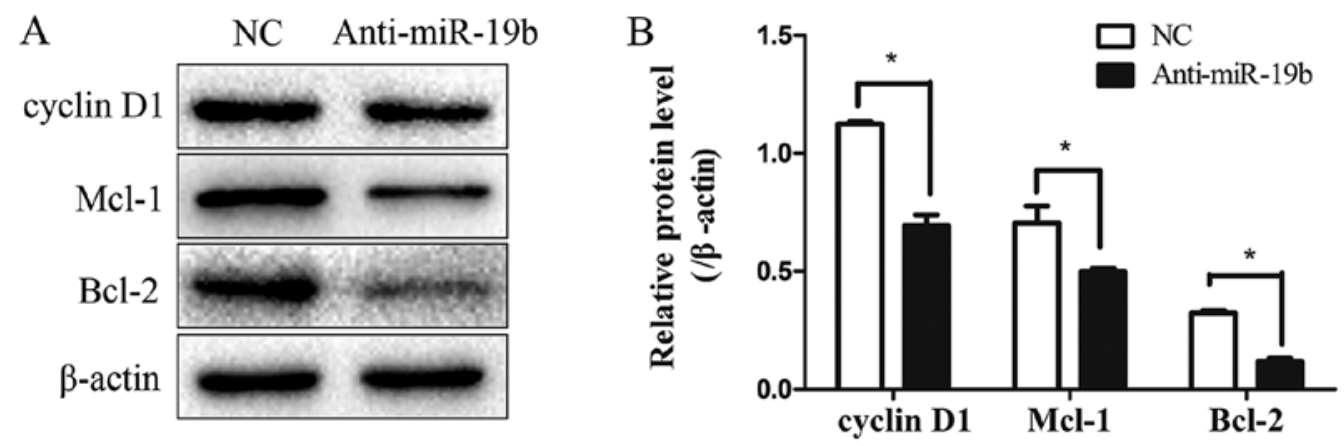

Figure 6. miR-19b inhibitor downregulated the expression of cyclin D1, Mcl-1 and Bcl-2. (A) C666-1 cells were transfected with the miR-19b inhibitor or NC and western blotting revealed that transcriptional targets of pSTAT3 (cyclin D1, Mcl-1 and Bcl-2) were downregulated by the miR-19b inhibitor compared with the NC 48 h post-transcription. (B) Protein expression was semi-quantified. * $\mathrm{P}<0.05$. miR, microRNA; Mcl-1; NC, negative control; p, phosphorylated; Mcl-1, myeloid leukemia protein 1 .

cluster facilitates malignant biological processes and modulates cancer-related pathways in NPC $(11,21,22)$.

The results of the present study indicated that miR-19b was upregulated in the majority of the NPC cell lines investigated compared with the nasopharyngeal epithelial cell line SXSW-1489. However, the role of miR-19b in NPC remains largely unknown. Therefore, in order to elucidate the functions of miR-19b in NPC cells, an miR-19b inhibitor was introduced into the NPC cell line C666-1. This decreased the proliferation, increased apoptosis and inhibited migration of C666-1 cells compared with the NC. These data are consistent with studies in several other malignancies $(8,9,22)$.

STAT3 is a member of the STAT protein family. STAT3 is phosphorylated by receptor-associated Janus kinases (JAK) when stimulated by cytokines and growth factors and forms homodimers or heterodimers, which are translocated into the cell nucleus where they act as transcriptional activators (23). STAT3 mediates the expression of a variety of genes in response to extracellular or intracellular stimuli (24), and thus plays a key role in cell growth, apoptosis, invasion and metastasis, immune escape and angiogenesis (25). The STAT3 signaling pathway was revealed to be constitutively activated in NPC (26). The involvement of STAT3 in cancer cell growth and invasion has been previously documented in NPC (27). Furthermore, STAT3 has been identified as a therapeutic target in NPC (27).

SOCS1 is a member of the STAT-induced STAT inhibitor (SSI) family, also known as the SOCS family (28). SSI family members are cytokine-inducible negative regulators of cytokine signaling (29). SOCS1 takes part in a negative feedback loop that involves the JAK/STAT3 signaling pathway to attenuate cytokine signaling (30). Additionally, SOCS1 is reported to be a target of miR-19b (31). The aforementioned studies suggest that miR-19b positively modulates the STAT3 signaling pathway by inhibiting SOCS1 expression. The results obtained in the present study showed that SOCS1 expression was upregulated following miR-19b inhibition in C666-1 cells. In addition, upregulation of SOCS1 was accompanied by the downregulation of pSTAT3, including both pSTAT3-Tyr705 and pSTAT3-Ser727, in C666-1 cells. The data implied that miR-19b plays a key role in STAT3 activation in NPC. STAT3 is activated through phosphorylation of Tyr705 in response to a number of factors, including interleukin-6 (32), platelet derived growth factor (10) and epidermal growth factor (33). STAT3 Ser727 is phosphorylated by various kinases (34). Phosphorylation at Tyr-705 leads to an increase in the transcriptional activity of STAT3. Serine phosphorylation is important for the formation of stable DNA-binding STAT3 homodimers and maximal transcriptional activity (35).

Phosphorylated STAT3 increases the expression of multiple downstream genes, which include cyclin D1, Bcl-2 and Mcl-1 (36). Cyclin D1 is proto-oncogene since it serves as a cell cycle regulator and is involved in the G1/S transition (37). Bcl-2 encodes an integral outer mitochondrial membrane protein that prevents apoptosis (38). Mcl-1 is a member of the Bcl-2 family, and is involved in the regulation of apoptosis and cell survival (39). In the present study, the expression of cyclin D1, Bcl-2 and Mcl-1 was downregulated in C666-1 cells following transfection with the miR-19b inhibitor. However, the downstream target genes of the STAT3 signaling pathway requires further investigation.

In conclusion, the present study revealed that inhibition of miR-19b attenuates the STAT3 signaling pathway and decreases the malignant biological behavior of the NPC cell line C666-1. Therefore, miR-19b may serve as potential therapeutic target for patients with NPC.

\section{Acknowledgements}

Not applicable.

\section{Funding}

The present study was supported by grants from the National Natural Science Foundation of China (grant nos. 81560441 and 81760491 to S.J. Xiao), the Natural Science Foundation of Guangxi Province of China (grant no. 2015GXNSFAA139131 to S.J. Xiao), and Innovation Project of Guangxi Graduate Education (grant no. YCSW2017211 to L.H. Bian).

\section{Availability of data and materials}

The datasets used and/or analyzed during the current study are available from the corresponding author on reasonable request.

\section{Authors' contributions}

$\mathrm{SX}$ and $\mathrm{XZ}$ contributed to the conception and design of the study. LB, XZ and SX drafted this manuscript. LB, JD, CZ, 
GS, XW, YY and XZ performed the experiments and analyzed the data. SX and $\mathrm{XZ}$ were involved in revising the manuscript. All authors read and approved the final manuscript.

\section{Ethics approval and consent to participate}

Not applicable.

\section{Patient consent for publication}

Not applicable.

\section{Competing interests}

The authors declare that they have no competing interests.

\section{References}

1. Chua MLK, Wee JTS, Hui EP and Chan ATC: Nasopharyngeal carcinoma. Lancet 387: 1012-1024, 2016.

2. Prawira A, Oosting SF, Chen TW, Delos Santos KA, Saluja R, Wang L, Siu LL, Chan KKW and Hansen AR: Systemic therapies for recurrent or metastatic nasopharyngeal carcinoma: A systematic review. Br J Cancer 117: 1743-1752, 2017.

3. Ambros V: The functions of animal microRNAs. Nature 431: 350-355, 2004.

4. Jansson MD and Lund AH: MicroRNA and cancer. Mol Oncol 6: 590-610, 2012.

5. Chen HC, Chen GH, Chen YH, Liao WL, Liu CY, Chang KP, Chang YS and Chen SJ: MicroRNA deregulation and pathway alterations in nasopharyngeal carcinoma. Br J Cancer 100: 1002-1011, 2009

6. Chen Y, Gao DY and Huang L: In vivo delivery of miRNAs for cancer therapy: Challenges and strategies. Adv Drug Deliv Rev 81: 128-141, 2015.

7. Braicu C, Calin GA and Berindan-Neagoe I: MicroRNAs and cancer therapy-from bystanders to major players. Curr Med Chem 20: 3561-3573, 2013.

8. Li J, Yang S, Yan W, Yang J, Qin YJ, Lin XL, Xie RY, Wang SC, Jin W, Gao F, et al: MicroRNA-19 triggers epithelial-mesenchymal transition of lung cancer cells accompanied by growth inhibition. Lab Invest 95: 1056-1070, 2015.

9. Li C, Zhang J, Ma Z, Zhang F and Yu W: miR-19b serves as a prognostic biomarker of breast cancer and promotes tumor progression through PI3K/AKT signaling pathway. Onco Targets Ther 11: 4087-4095, 2018

10. Vij N, Sharma A, Thakkar M, Sinha S and Mohan RR: PDGF-driven proliferation, migration, and IL8 chemokine secretion in human corneal fibroblasts involve JAK2-STAT3 signaling pathway. Mol Vis 14: 1020-1027, 2008.

11. Ma F, Wang Z, Wang J, Liu X and Hu C: MicroRNA-19a promotes nasopharyngeal carcinoma by targeting transforming growth factor $\beta$ receptor 2. Exp Ther Med 14: 1419-1426, 2017.

12. Hsu CY, Yi YH, Chang KP, Chang YS, Chen SJ and Chen HC: The epstein-barr virus-encoded MicroRNA MiR-BART9 Promotes Tumor Metastasis by Targeting E-Cadherin in nasopharyngeal carcinoma. PLoS Pathog 10: e1003974, 2014

13. Lin TY, Chen Y, Jia JS, Zhou C, Lian M, Wen YT, Li XY, Chen HW, Lin XL,Zhang XL, et al: Loss of Cirbp expression is correlated with the malignant progression and poor prognosis in nasopharyngeal carcinoma. Cancer Manag Res 11: 6959-6969, 2019.

14. Zhao M, Luo R, Liu Y, Gao L, Fu Z, Fu Q, Luo X, Chen Y, Deng X, Liang Z, et al: MiR-3188 regulates nasopharyngeal carcinoma proliferation and chemosensitivity through a FOXO1-modulated positive feedback loop with mTOR-p-PI3K/AKT-c-JUN. Nat Commun 7: 11309-11322, 2016.

15. Li X, Zhao Z, Zhang X, Yang S, Lin X, Yang X, Lin X, Shi J, Wang S, Zhao W, et al: Klf4 reduces stemness phenotype, triggers mesenchymal-epithelial transition (MET)-like molecular changes, and prevents tumor progression in nasopharygeal carcinoma. Oncotarget 8: 93924-93941, 2017.

16. Xiao K, Yu Z, Li X, Li X, Tang K, Tu C, Qi P, Liao Q, Chen P, Zeng Z, et al: Genome-wide analysis of epstein-barr virus (EBV) integration and strain in C666-1 and raji cells. J Cancer 7: 214-224, 2016 .
17. Davey GM, Heath WR and Starr R: SOCS1: A potent and multifaceted regulator of cytokines and cell-mediated inflammation. Tissue Antigens 67: 1-9, 2006.

18. Liu M, Yang R, Urrehman U, Ye C, Yan X, Cui S, Hong Y, Gu Y, Liu Y, Zhao C, et al: MiR-19b suppresses PTPRG to promote breast tumorigenesis. Oncotarget 7: 64100-64108, 2016.

19. Wang H, Xiong M, Hu Y, Sun Y and Ma Q: MicroRNA-19b inhibits proliferation of gastric cancer cells by targeting B-cell CLL/lymphoma 3. Oncol Rep 36: 2079-2086, 2016.

20. Li X, Wang FS, Wu ZY, Lin JL, Lan WB and Lin JH: MicroRNA-19b targets Mfn1 to inhibit Mfn1-induced apoptosis in osteosarcoma cells. Neoplasma 61: 265-273, 2014.

21. Fan Y, Yin S, Hao Y, Yang J, Zhang H, Sun C, Ma M, Chang Q and Xi JJ: miR-19b promotes tumor growth and metastasis via targeting TP53. RNA 20: 765-772, 2014.

22. Luo Z, Dai Y, Zhang L, Jiang C, Li Z, Yang J, McCarthy JB, She X, Zhang W, Ma J, et al: MiR-18a promotes malignant progression by impairing microRNA biogenesis in nasopharyngeal carcinoma. Carcinogenesis 34: 415-425, 2013.

23. Cheng GZ, Zhang W, Sun M, Wang Q, Coppola D, Mansour M, $\mathrm{Xu} \mathrm{LM}$, Costanzo C, Cheng JQ and Wang LH: Twist is transcriptionally induced by activation of STAT3 and mediates STAT3 oncogenic function. J Biol Chem 283: 14665-14673, 2008.

24. Ferguson SD, Srinivasan VM and Heimberger AB: The role of STAT3 in tumor-mediated immune suppression. J Neurooncol 123: 385-394, 2015.

25. Teng Y, Ross JL and Cowell JK: The involvement of JAK-STAT3 in cell motility, invasion, and metastasis. JAKSTAT 3: e28086, 2014.

26. Lo AK, Lo KW, Tsao SW, Wong HL, Hui JW, To KF, Hayward DS, Chui YL, Lau YL, Takada K and Huang DP: Epstein-barr virus infection alters cellular signal cascades in human nasopharyngeal epithelial cells. Neoplasia 8: 173-180, 2006.

27. Ho Y, Tsao SW, Zeng M and Lui VW: STAT3 as a therapeutic target for Epstein-Barr virus (EBV): Associated nasopharyngeal carcinoma. Cancer Lett 330: 141-149, 2013.

28. Naka T, Narazaki M, Hirata M, Matsumoto T, Minamoto S, Aono A, Nishimoto N, Kajita T, Taga T, Yoshizaki K, et al: Structure and functionof a new STAT-induced STAT inhibitor. Nature 387: 924-929, 1997.

29. Hamanaka I, Saito Y, Yasukawa H, Kishimoto I, Kuwahara K, Miyamoto Y, Harada M, Ogawa E, Kajiyama N, Takahashi N, et al: Induction of JAB/SOCS-1/SSI-1 and CIS3/SOCS-3/SSI-3 is involved in gp130 resistance in cardiovascular system in rat treated with cardiotrophin-1 in vivo. Circ Res 88: 727-732, 2001.

30. Ben-Zvi T, Yayon A, Gertler A and Monsonego-Ornan E: Suppressors of cytokine signaling (SOCS) 1 and SOCS3 interact with and modulate fibroblast growth factor receptor signaling. J Cell Sci 2: 380-387, 2006

31. Mignacca L, Saint-Germain E, Benoit A, Bourdeau V, Moro A and Ferbeyre G: Sponges against miR-19 and miR-155 reactivate the p53-Socs1 axis in hematopoietic cancers. Cytokine 82: 80-86, 2016.

32. Huang TQ, Willis MS and Meissner G: IL-6/STAT3 signaling in mice with dysfunctional type-2 ryanodine receptor. JAKSTAT 4: el158379, 2016.

33. Wang Y, van Boxel-Dezaire AH, Cheon H, Yang J and Stark GR: STAT3 activation in response to IL-6 is prolonged by the binding of IL-6 receptor to EGF receptor. Proc Natl Acad Sci USA 110: 16975-16980, 2013.

34. Parys JB: The multifaceted STAT3: How a transcription factor regulates $\mathrm{Ca}^{2+}$ signaling via a degradative pathway. Cell Calcium 76: 137-139, 2018.

35. Yokogami K, Wakisaka S, Avruch J and Reeves SA: Serine phosphorylation and maximal activation of STAT3 during CNTF signaling is mediated by the rapamycin target mTOR. Curr Biol 10: 47-50, 2000.

36. Banerjee $\mathrm{K}$ and Resat $\mathrm{H}$ : Constitutive activation of STAT3 in breast cancer cells: A review. Int J Cancer 138: 2570-2578, 2016.

37. Pardee AB: G1 events and regulation of cell proliferation. Science 246: 603-608, 1989

38. Lam M, Dubyak G, Chen L, Nuñez G, Miesfeld RL and Distelhorst CW: Evidence that BCL-2 represses apoptosis by regulating endoplasmic reticulum-associated $\mathrm{Ca} 2+$ fluxes. Proc Natl Acad Sci USA 91: 6569-6573, 1994.

39. Liu Q and Gehring K: Heterodimerization of BAK and MCL-1 Activated by Detergent Micelles. J Biol Chem 285: 41202-41210, 2010.

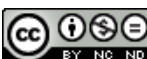

This work is licensed under a Creative Commons Attribution-NonCommercial-NoDerivatives 4.0 International (CC BY-NC-ND 4.0) License. 